\title{
Influence on a Consumer Unit Power Factor Provided by the Connection of a SHPP in Shunt with the Utility Power
}

\author{
Arnulfo Barroso de Vasconcellos ${ }^{1}$, Dr.; Raul Vitor Arantes Monteiro ${ }^{1}$, Esp.; Jéssica Romeiro de Carvalho ${ }^{1}$, Acad.; \\ Marina Silva Camillo de Carvalho ${ }^{1}$, Acad.; Tisciane Perpétuo e Oliveira ${ }^{1}$, Acad; Teresa Irene Ribeiro de Carvalho Malheiro, \\ $\mathrm{PhD}^{2}$. \\ ${ }^{1}$ Faculty of Architecture, Engineering and Technology, UFMT -Federal University of Mato Grosso - Cuiabá/MT - Av. \\ Fernando Correa da Costa, nº 2367 - Bairro Boa Esperança. Cuiabá - MT, Brazil \\ Phone: +55 (65) 3615-8000, e-mail: Arnulfo@ufmt.br, rauldvm@terra.com.br, jessica.romeiro@ hotmail.com, \\ marsccarvalho@gmail.com, tisciane_perpetuo@hotmail.com . \\ ${ }^{2}$ Federal Institution of Education, Science and Technology of Mato Grosso - IFMT - Avenida Sen. Filinto Müller , 953 \\ Phone: +55 (65) 3616-4100 ,e-mail: malheiro.teresa@gmail .
}

\begin{abstract}
.
Production growth of agribusiness in the state of Mato Grosso increased the deployment of industries in several regions of the state, regions which the hydraulic potential is favorable to the installation of small hydro power plants (SHPP) that helps in the supply of the active power demand of these consumer units (UC). This article analyzes a consumer unit of Class A customer, relative to the agribusiness, with an industrial park consisting of soybean storage, processing unit of cotton and cottonseed crushing, what was initially only connected to the electric utility bus. After building a SHP with two generators at the UC, this generation was connected in parallel with the power utility bus after the system power measurement. In this work is analyzed the influence of the entrance of SHPP in surplus of UC's reactive power, discussing the need for parallel generation to operate with the power factor in conformity with the load's reactive demand requested by the UC of the utility bus to improve the power factor recorded by the measurement system and eliminate the excess of reactive energy on the energy bill, similarly with the effect of a connection of a variable capacitor bank downstream the utility measuring for regulating the power factor seen by the meter.
\end{abstract}

\section{Key words}

Reactive Demand, Surplus of Reactive Power, Power Factor, Generation and Energy Measurement.

\section{Introduction}

The state of Mato Grosso has its drainage network covering the Amazon's and Tocantins' watersheds to the north, and the basin of the Paraguay to the south of the state. Covers the highlands of Campo Verde, Primavera do Leste and Parecis as the great dividers of the waters, where are located the sources of the main forming of the rivers that make up these basins.
The state is the second largest generator for Small Hydro Power (SHP - with installed capacity up to 30 MW), and the fifth largest with production by Central Generating Plants (CGHs - with installed capacity up to 1 MW) as can be seen at (ANEEL, 2011). According to the National Electric Energy Agency (ANEEL), altogether 61 SHPs are in operation with the capacity to generate 808.19 MW and 40 CGHs capable of generating 21.28 MW. In total, considering other energy arrays, Mato Grosso has the capacity to generate $2,804,909 \mathrm{~kW}$, representing $2.24 \%$ of national output $(125,026,340.93$ $\mathrm{kW})$. Of this total, $71.08 \%(1,993,884 \mathrm{~kW})$ comes from hydroelectric sources, and $28.81 \%(808,186 \mathrm{~kW})$ of power plants and $0.76 \%(21,278 \mathrm{~kW})$ the CGHs.

As it turns out, the hydraulic potential of Mato Grosso is large and attracts investment in electric power production through deployment of small generating plants. The lure of the private sector in the generation of hydroelectric power in almost all Brazilian territory was encouraged after the government promoted institutional and regulatory changes to encourage the generation of electricity through these, it is proven by the number of new ventures. ANEEL data indicate that six power plants are under construction in Mato Grosso and contribute 67.6 MW. Another 17 projects (being fifteen SHP and two CGHs) were granted between 1998 and 2004, and when constructed, will contribute 197.3 MW for generation of the state.

Considering the national scene for the past seven years, the installed capacity of the small plants of the country has grown fourfold. Comparing data (Encomind, 2011) with those provided by ANEEL, in 2003 the power of the SHP totaled 1,151 GW, and in 2013, granted the power to $4.64 \mathrm{GW}$. The involvement of SHP in the energy mix has increased from $1.22 \%$ to $3.66 \%$ in the same period and the number of plants increased from 241 to 462 . As for the CGHs, 424 are in operation, one under 
construction and 53 granted. Hence the interest in studying the effects of distributed generation on the system is not just restricted to the state of Mato Grosso, but the whole country.

As most enterprises in small mills are made by private initiative to meet loads of companies themselves and the excess production available to the national system for "spot" market, it is interesting to study how the operation of such influences on the central system pricing of electricity, mainly because the majority of young generation is done in unity power factor, since only the active power produced is sold.

This article analyzes the operation of a small hydropower plant in parallel with the utility bus power system. Showing how a SHP operating at unity power factor, can cause oscillation of power factor recorded by the utility meter and cause a large surplus of reactive, harmful to the consumer unit. Whereas at one time of the year, known as the wet season, the SHP produces a maximum demand of active power due to the large volume of water in its reservoir and removes a small demand of active power from the utility bus, thereby decreasing the power factor seen by the measurement system. However, little precipitation during the rainy known as the dry period, UC removes a large portion of demand from the utility that provides an improved power factor seen by the meter system. As in the case analyzed, not always the generation of SHP is sufficient to meet demand of active power requested by the load, the consumer unit is forced to keep the bus in parallel with the utility power system. However Normative Resolution 414 (ANEEL, 2010), which establishes the general conditions of supply of electricity updated and consolidated manner, says that for consumers in group A, power factor reference "fr", inductive or capacitive, has a minimum allowed value of 0.92 . Considering the large percentage of $\mathrm{CGH}$ and SHP currently operating in parallel with the electric utilities, makes new discussions on emerging academic field about how and how relevant will this influence the surplus of reactive power measurement recorded in the UC system. 96, Vol. 1, pp. 120-126.

\section{Development}

\section{A. Characteristics of Consumer Unit Prior to connection of SHP in the utility's Energy Bus}

Initially, the UC was fed through a transmission line of $34.5 \mathrm{kV}$ radial length of $130 \mathrm{~km}$, which is composed of several UC power transformer as illustrated in line diagram of figure 1.

In figure 1 we can notice the presence of several loads of seasonal characteristics in the $34.5 \mathrm{kV}$ bus, as structures for grain storage, grain dryers, crushing cotton seed, cotton processing units, etc.

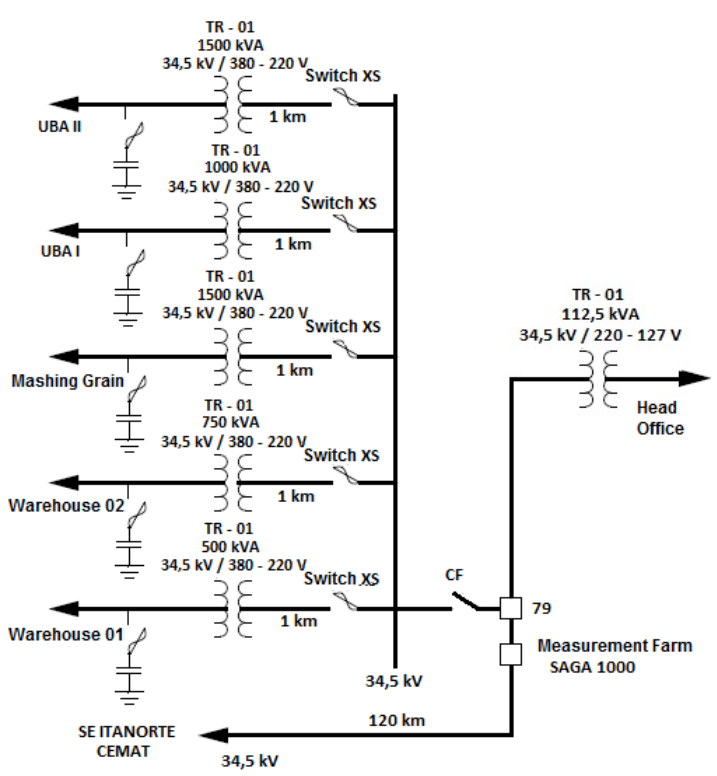

Fig. 1 - Single Line Diagram power of UC.

The demand of active power required by the electric system of these charges during normal operation is around an average value of $2,400 \mathrm{~kW}$, so the UC has a contract of demand on Horo-Seasonal Green rate with power utility of $2,300 \mathrm{~kW}$.

As seen in figure 1 all the loads connected to the bus being predominantly composed of induction motors are compensated by capacitor banks, this also entails to improve the level of tension once the UC feeding system is radial. Analyzing the value of the average reactive power requested by the utility meter in UC yielded an average of $800 \mathrm{KVAR}$ as illustrated in figure 2 for an average demand of $2,400 \mathrm{~kW}$ thus providing a medium power factor 0,94 as shown in figure 3 .

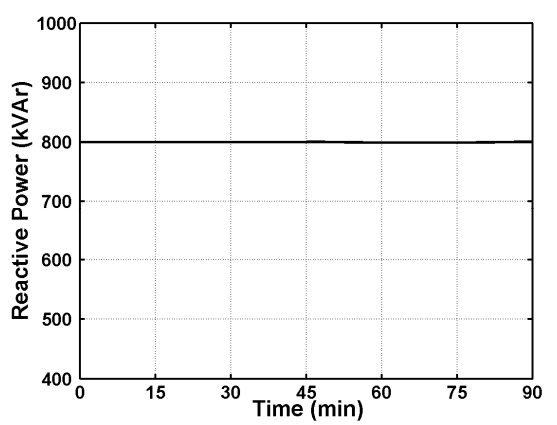

Fig. 2 - Profile of the average reactive power of the UC before entering the SHP

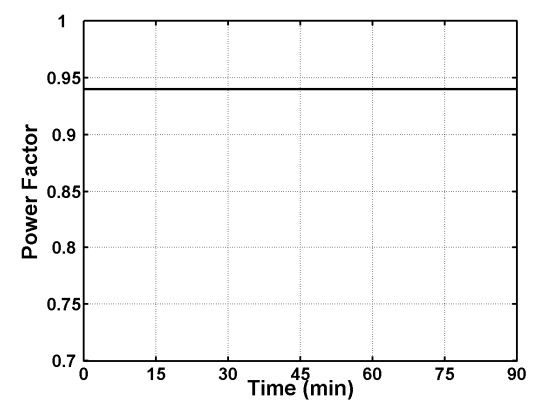

Fig. 3 - Profile of the average power factor of the UC before entering the SHP. 


\section{B. Characteristics of Consumer Unit After Connecting SHP in Bus.}

Next to this Consumer Unit was built a SHP with two generators with generating capacity of an average active power demand of $1.5 \mathrm{MW}$ as illustrated in figure 4 .

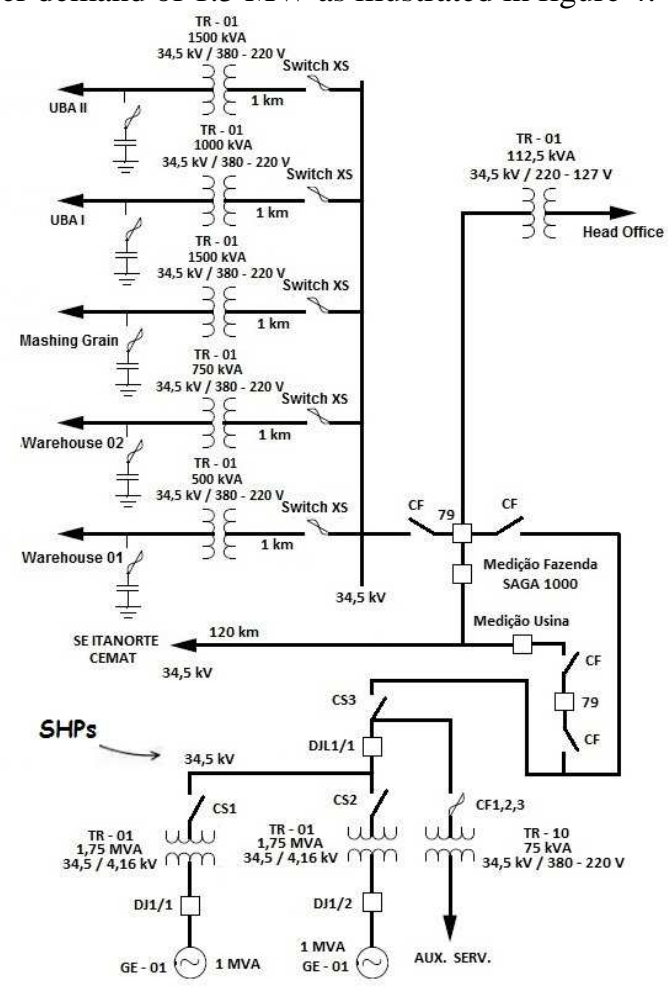

Fig. 4. Line diagram of the power supply of UC with the connection of SHP.

This generation was connected to $34.5 \mathrm{kV}$ bus UC after the measurement of the utility system shown in figure 4 , providing an average power demand of $1.5 \mathrm{MW}$ at unity power factor, and this level of demand generated by limited water volume of the reservoir of SHP in the current period. It has been found that providing an average demand of 1.5 MW from the SHP to $34.5 \mathrm{kV}$ UC bus, was reduced the active power demand requested by the dealer for an average of $900 \mathrm{~kW}$ (Albuquerque, 1993), to the behavior of the system for a certain period (10/08/2013) of portion of the load installed in operation at UC where there was an average demand of $2,400 \mathrm{~kW}$. Under these operating conditions of the consumer unit, the medium power factor which was around 0.94 before induction was reduced to 0.74 inductive, this situation is provided by the entry into operation of the SHP in the $34.5 \mathrm{kV}$ bus with an average demand $1.5 \mathrm{MW}$ at unity power factor (Falcone, 1979). Under these conditions the UC reduced the power demand required by the licensee to $66 \%$ keeping the same percentage of reactive demand withdrawal of the utility system, providing thus a significant decrease in power factor recorded in the utility meter causing an increase in surplus energy reactive.

Within this context one of the solutions would be to operate the SHP generating around $30 \%$ of capacitive reactive and not at unity power factor, thus leading to a reduced inductive reactive power required from the dealership and putting the power factor within the time limits established by the legislation, thus avoiding the payment of excess reactive energy in the electricity bill of the consumer unit.

However, this method has the disadvantage of reducing the active power generated by the plant, since the power factor was changed from unit (maximum active power generated) to 0.7 .

\section{Computational simulation UC with capacitor bank after the measurement of the Utility}

With the aim of analyzing the behavior of the power factor on measuring system from UC when a capacitor bank is installed after the measuring of the dealership, was made computational modeling and simulation of Consumer Unit in question by using the ATP Draw software.

Then the power of a variable capacitor bank was calculated to be installed through a transformer in 34.5 $\mathrm{kV}$ bus after the dealership measurement to reactive compensation in order to maintain the power factor within the limits of the law, independent of number of loads connected to "B" bus of figure 5. For this was added a set of six capacitor banks of $30 \mathrm{kVAR}$ each individually switched, totaling $180 \mathrm{kVAR}$ capacitive.

Thus, the simulated full-line diagram is shown in figure 5 .

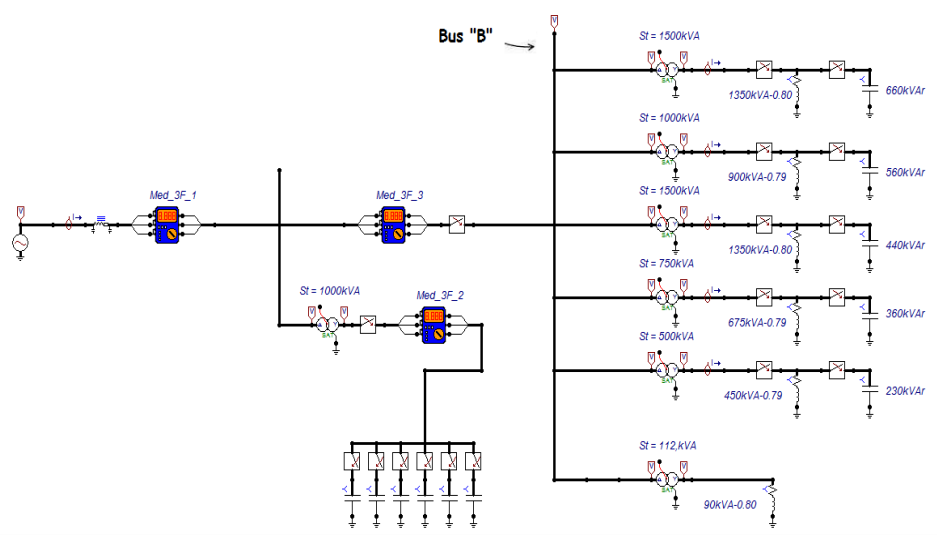

Fig. 5. Complete system simulation.

After the one-line diagram representation of the UC at ATP Draw software illustrated in figure 5 were performed simulations involving multiple input and output loads in the "B" bus of Consumer Unit, with the aim of monitoring the behavior of the power factor at the utility meter. The first simulation was performed with all banks and linked with the presence of all the loads on the "B" bus. Simulation results for this situation are illustrated in figures 6 and 7 which shows the power factor and the waveforms of the voltage and current of phase "a". 


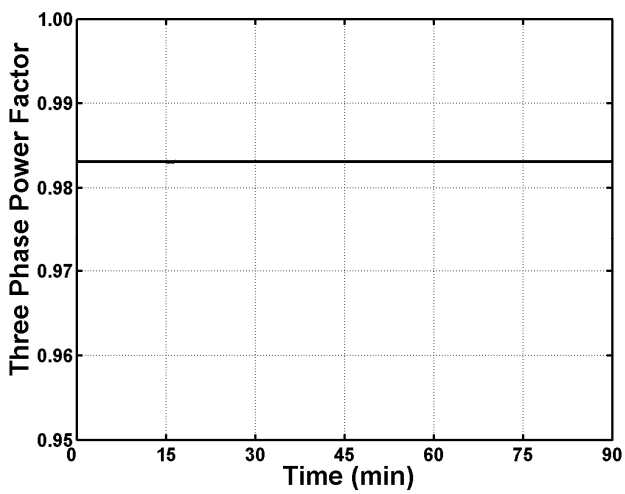

Fig. 6 - Profile of the power factor associated with all banks and the presence of all the loads on the "B" bus.

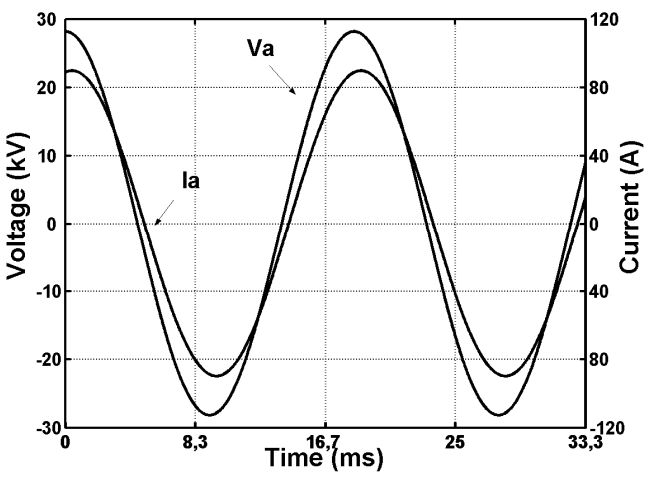

Fig. 7 - Current Waveform on phase "a" in relation to the voltage- connected with the presence of all the loads on the "B" bus.

Analyzing figure 6 it is observed that the power factor remained close to unity, and reviewing figure 7 , the current waveform of phase "a" relative to the voltage of the same phase, it turns out that the factor power is inductive.

From this simulation, we analyzed the state of the system with all the banks permanently attached while the load was reduced on the bus "B" of figures 6 and 7 (some charges were turned off). The behavior of the power factor in the time for $80 \%$ of the load shutdown present in the "B" bus can be observed from figure 8 .

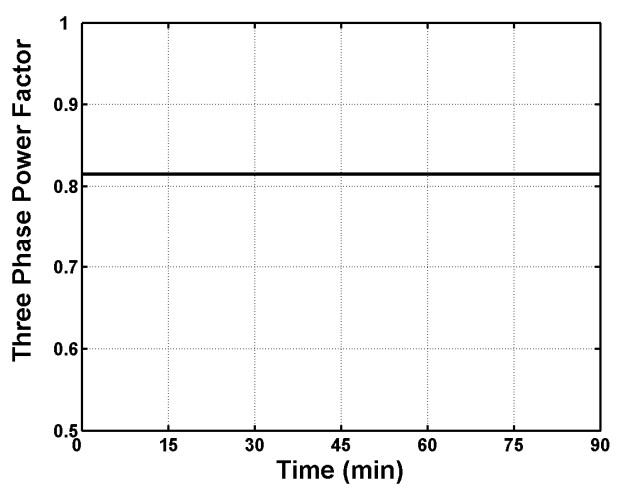

Fig. 8 - Profile of power factor with all banks connected with shutting down $80 \%$ of loads in the "B" bus.

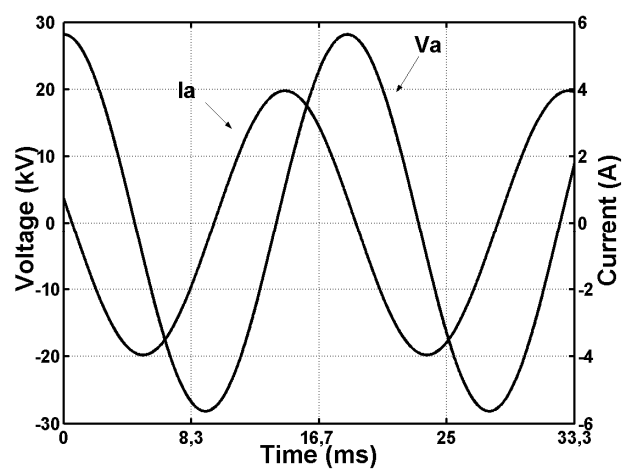

Fig. 9 - Current waveform phase "a" in relation to the shutdown voltage $80 \%$ of loads on the bus "B".

Figure 8 shows the profile of the power factor, with permanently connected capacitor banks and $80 \%$ of the load off, and shows that the power factor seen by the meter dealership went from 0.98 inductive to 0.86 capacitive.

The capacitive characteristic of the power factor is found by analyzing the waveforms of voltage and current in phase "a" at the input of "B" bus shown in figure 9, it is noted that the current is advanced in relation to the voltage due to shutdown loads. Thus we conclude that the factor below 0.92 capacitive power in the period of 23hours and 30minutes to 6hours and 30minutes and the corresponding capacitive morning hours will result in the collection of excess reactive consumer units.

However, to prevent the power factor becomes capacitive by removing a set of loads of "B" bus, simulations with capacitor banks varying as the load were performed, by removing a part of the load, part capacitor banks will also be removed.

Within this context, simulations were performed again with the removal of $80 \%$ of loads of "B" bus, but keeping only two capacitor banks switched to $30 \mathrm{KVAR}$ each. Figure 10 illustrates the power factor seen by the utility meter and may be noted that, unlike the previous case, remained above 0.92 inductive, thereby avoiding the payment of reactive excess on schedules both inductive as capacitive. Figure 11 illustrates the behavior of the waveforms of the voltage and current for phase "a", one can observe the inductive characteristic of the power factor of UC bus 'B', i.e. voltage lags in relation of the current.

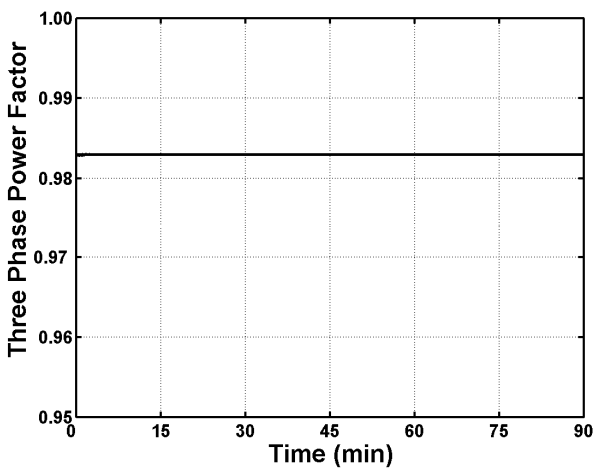

Fig. 10 - Profile of power factor with two capacitor banks connected with shutting down $80 \%$ of loads in the "B" bus. 


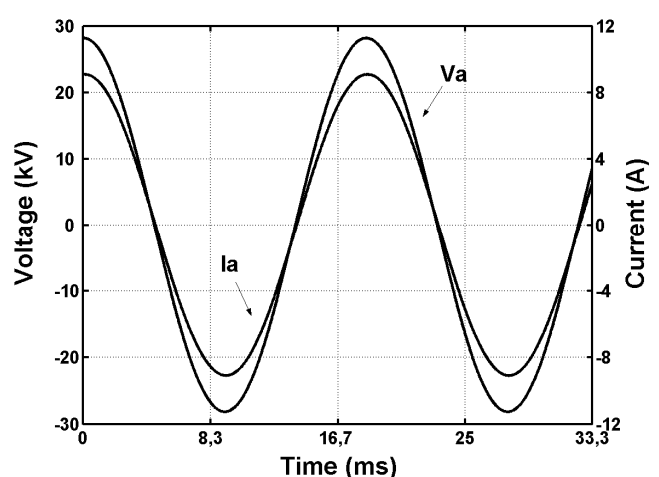

Fig. 11 - Waveform of current in phase "a" in relation to the voltage with the shutdown of $80 \%$ of loads in bus "B" and two capacitor banks connected.

Thus, it was found that it is possible to maintain the power factor levels within the limits of the law when the most significant loads are removed from the "B" bus in figure 5 and that part of the capacitor bank are also removed.

\section{Conclusion}

This paper analyzed the behavior of the demand of a consumer unit serviced by a SHP in parallel with the bus of a utility company, which due to rainfall characteristics at the right time of year known as the wet season because the SHP produce a maximum of active power demand due to the large volume of water in its reservoir, UC withdrew a small demand of active power from the utility bus thereby decreasing the power factor seen by the same measurement system. However, during the period of low rainfall, dry period known as UC withdrew a large portion of demand from the utility system which provided an improvement in the power factor seen by the meter.

As in the case analyzed, not always the generation of the SHP is sufficient to meet demand of active power requested by the load, the consumer unit is forced to keep the bus in parallel with the utility power system. Within this context, several simulations using the software ATP Draw involving input and output loads of the UC bus with the aim of analyzing the behavior of power factor at the utility meter were performed.

Thus, it was shown that the use of automatic capacitor banks downstream of the measuring system of the dealership can be an effective device for regulating the power factor measurements of Consumer Units operating with internally generated energy through systems and CGH and SHP in parallel with the dealership and can thus keep the generation plant at unity power factor.

This method can also be applied to UCs that have intermittent behavior of loads and, for any input of distributed generation in parallel with the bus of the electric utility, such as wind generation that is booming in Brazil.

Therefore, the influence of the connection of distributed generation on the buses of consumer units fed by the utility requires operation studies to avoid changes in the values of excess reactive energy recorded by electricity meters.

\section{REFERENCES}

[1] ANEEL Normative Resolution No. 461, sub module 26 , November 11, 2011

[2] http://www.aneel.gov.br/aplicacoes/ResumoEstadual/ResumoEsta dual.cfm.

[3] http://www.encomind.com.br/TNX/conteudo.php?sid=18\&cid=12 14

[4] http://www.aneel.gov.br/aplicacoes/capacidadebrasil/capacidadebr asil.cfm

[5] ANEEL Normative Resolution \# 414, September 9, 2010.

[6] ANEEL, Procedures for Electric Energy Distribution in the National Electricity System (Prodist), Module 5.

[7] ALBUQUERQUE RO, Analysis of Alternating Current Circuits, 10th ed., 1993.

[8] Falcone, AG, Electromechanical - Electric Rotating Machinery, Vol 2, 1979. 